\title{
Intracameral dexamethasone injection in the treatment of cataract surgery induced inflammation: design, development, and place in therapy
}

This article was published in the following Dove Press journal:

Clinical Ophthalmology

Tirth J Shah'

Mandi D Conway ${ }^{1,2}$

Gholam A Peyman ${ }^{1,2}$

'Department of Ophthalmology, University of Arizona College of Medicine, Phoenix, Arizona, USA;

${ }^{2}$ Department of Ophthalmology, Tulane University College of Medicine, New Orleans, Louisiana, USA
Correspondence: Gholam A Peyman Department of Ophthalmology, University of Arizona College of Medicine Phoenix Campus, I0650 W, Tropicana

Circle, Sun City, AZ 8535I, USA

Tel +l 6237607166

Email gpeymanI@yahoo.com

\begin{abstract}
Cataract surgery is one of the most commonly performed surgeries worldwide, with nearly 20 million cases annually. Appropriate prophylaxis after cataract surgery can contribute to a safe and quick visual recovery with high patient satisfaction. Despite being the current standard of care, the use of multiple postoperative eye drops can create a significant burden on these patients, contributing to documented and significant non-adherence to the postoperative regimen. Over the past 25 years, there have been a few studies analyzing the use of intracameral dexamethasone (DXM) in controlling inflammation following cataract surgery. This review explores various drug delivery approaches for managing intraocular inflammation after cataract surgery, documenting the strengths and weaknesses of these options and examining the role of intracameral DXM (among these other strategies) in controlling postoperative intraocular inflammation. Intracameral DXM has a particular advantage over topical steroids in possibly decreasing postoperative inflammatory symptoms and objective anterior cell and flare scores. Compared to topical steroids, there may be a slightly less theoretical risk of significant intraocular pressure spikes and systemic absorption. In addition, surveys indicate patients prefer an intraoperative intracameral injection over a self-administered postoperative eye drop regimen. However, there are several adverse effects associated with intracameral DXM delivery that are not seen with the noninvasive topical approach. Although it is unlikely that intracameral DXM will replace topical medications as the standard management for postoperative inflammation, it is seemingly another safe and effective strategy for controlling postoperative inflammation after routine cataract surgery.
\end{abstract}

Keywords: intracameral dexamethasone, intraocular steroids, cataract surgery, inflammation, topical steroids, Dexycu ${ }^{\circledR}$, Surodex ${ }^{\circledR}$, inflammation, intraocular pressure cataract surgery

\section{Introduction}

Vision impairment due to cataract inflicts 20 million individuals worldwide and represents nearly half the individuals with blindness. ${ }^{1,2}$ Since visual impairment from cataracts cannot be corrected by spectacle wear, contact lenses or medical treatment, cataract extraction is the only option for patients to clear optical media. Cataract surgery is one of the most commonly performed and most successful surgical procedures worldwide. ${ }^{3}$ As with any intraocular surgery, varying degrees of inflammation occur secondary to mechanical damage from the surgical tissue manipulation and a mild reaction to the foreign intraocular lens (IOL), which may result in significant postoperative inflammation. ${ }^{4,5}$ The consequences of postoperative inflammation are cystoid macular 
edema, increased intraocular pressure, posterior capsular opacification, and protein leakage from the breakdown of the blood-aqueous barrier. ${ }^{6}$ Even in uncomplicated cataract surgeries, the inflammatory sequelae may occasionally lead to chronic uveitis and fibrin formation contributing to an undesirable surgical outcome. ${ }^{7}$

In a recent study, $34 \%$ of patients reported eye pain during the first 24 hours following cataract surgery and 10\% of patients reported discomfort for as long as 6 weeks after surgery. ${ }^{8}$ Postoperative visual symptoms attributed to inflammation include dryness, irritation, and pain, which may delay the postoperative recovery and affect patient satisfaction. ${ }^{9-11}$ Hence, addressing the inflammation is an important part of the postoperative care.

As early as 1950, the beneficial effect of corticosteroid therapy on inflammatory ocular disease was recognized. It has been well demonstrated that topical corticosteroids and non-steroidal anti-inflammatory drugs (NSAIDs) are effective drugs compared to placebo for decreasing anterior chamber inflammation and its sequelae. ${ }^{5}$ In 2012, a survey of surgeons to the 132 members of the Association of Veterans Affairs Ophthalmologists reported that $97 \%$ of respondents were prescribed corticosteroid drops and or NSAID drops after cataract surgery, ${ }^{12}$ supporting this regimen as a Standard of Care (SOC) in postoperative pharmaceutical treatment after cataract surgery.

Despite the current standard regimen of treatment, the use of postoperative eye drops creates a significant burden on these patients, especially since most postoperative cataract surgery patients are elderly with a limited ability to adhere to this treatment schedule. A study monitoring patient compliance with topical treatment after glaucoma surgery showed that nearly $30 \%$ of patients did not adhere to the treatment regimen. ${ }^{13}$ Some studies imply the level of drug wastage and premature discontinuation of therapy may be higher in cataract surgery patients than any other ophthalmic surgeries. ${ }^{14}$ Thus, there is a crucial need to develop simpler ways to provide postoperative drug delivery in a safe and effective manner.

The toxicity of intraocular dexamethasone (DXM) was studied in 1974 in the treatment of inflammatory diseases of the eye by Graham and Peyman. ${ }^{15}$ However, in the past two decades, there have been a small number of studies analyzing the use of intracameral DXM in controlling post-cataract surgery inflammation. ${ }^{16-22}$ This strategy offers cataract surgeons the option of a single injection of DXM into the eye at the end of surgery. In order to improve the delivery method, two biodegradable DXM delivery systems for managing inflammation following cataract surgery have been developed, one of which received recent approval by the US Food and Drug Administration (FDA). These devices are intended to improve bioavailability, reduce non-adherence, and eliminate dosing miscalculations that can occur in the geriatric population. This review will compare the rationale of various routes of DXM administration in controlling postcataract surgery inflammation and highlight the strengths and weaknesses of each method with a special emphasis on topical and intracameral DXM usage in various clinical studies. Importantly, it will highlight studies about the effectiveness and safety of intracameral DXM as well as assessing its role in the therapeutic management of inflammation after cataract surgery. ${ }^{16-22}$

\section{Mechanism of action}

Dexamethasone is one of the most potent glucocorticoid preparations that downregulates a variety of inflammatory mediators. Similar to all glucocorticoids, DXM binds to the intracellular glucocorticoid receptor $\alpha$ after dissociation of the receptor from heat shock protein $90 .{ }^{23,24}$ This promotes translocation of the complex to the nucleus where it acts as a transcription factor to induce the expression of genes with anti-inflammatory effects, such as lipocortin, IL-1 receptor antagonist, IL-10, and I $\kappa \mathrm{B} \alpha$ genes. ${ }^{25,26}$ In addition, DXM inhibits upstream signaling through NF- $\mathrm{KB}$ and AP1 pathways, which prevents production of inflammatory cytokines (ie, TNF- $\alpha$, IFN- $\gamma$, IL-6, etc.), chemokines (ie, CXCL-10, CCL5, etc.), and metalloproteinases (ie, MMP-1, MMP-2, MMP-3, MMP-9, etc.). ${ }^{25}$ In various types of experimental and clinical ocular inflammatory situations, there is an increase in prostaglandins in the aqueous humor and tear film.27,28 Importantly, we know from prior studies that prostaglandins play an important role in mediating pain, hyperemia, photophobia, lacrimation, and decreased vision from cystoid macular edema, symptoms that are commonly exhibited in post-cataract eyes. ${ }^{29,30} \mathrm{DXM}$, similar to all corticosteroids, inhibits the production of prostaglandins by blocking the enzymatic activity of phospholipase $\mathrm{A}_{2}$-mediated release of arachidonic acid from cell membranes. ${ }^{31}$ Experimental studies of inflammation have established that prostaglandin production is significantly higher in inflamed eyes compared to the non-inflamed baseline state. ${ }^{31}$ For instance, in a study of endotoxin-induced uveitis in rabbits, a 60-fold-induction in the amount of prostaglandin was detected in the aqueous humor. ${ }^{27}$ In contrast to cyclooxygenase-1 (COX-1) enzyme which is responsible for prostaglandin synthesis under baseline physiologic conditions and appears to maintain homeostasis, cyclooxygenase-2 (COX-2) is increasingly expressed after stimulation with proinflammatory cytokines, 
such as interleukin 1 (IL-1), tumor necrosis factor-alpha (TNF-alpha) and endotoxin in many cell types, including endothelial cells and monocytes/macrophages. ${ }^{32}$ Therefore, one of the most important anti-inflammatory roles of DXM is suppression of COX-2 mediated production of inflammatory prostaglandins. In animal models of endotoxininduced inflammation, simultaneous administration of DXM resulted in a five-fold decrease in prostaglandin synthesis. ${ }^{27}$ Consequently, through various mechanisms of action (Figure 1), DXM reduces some of the inflammatory-induced

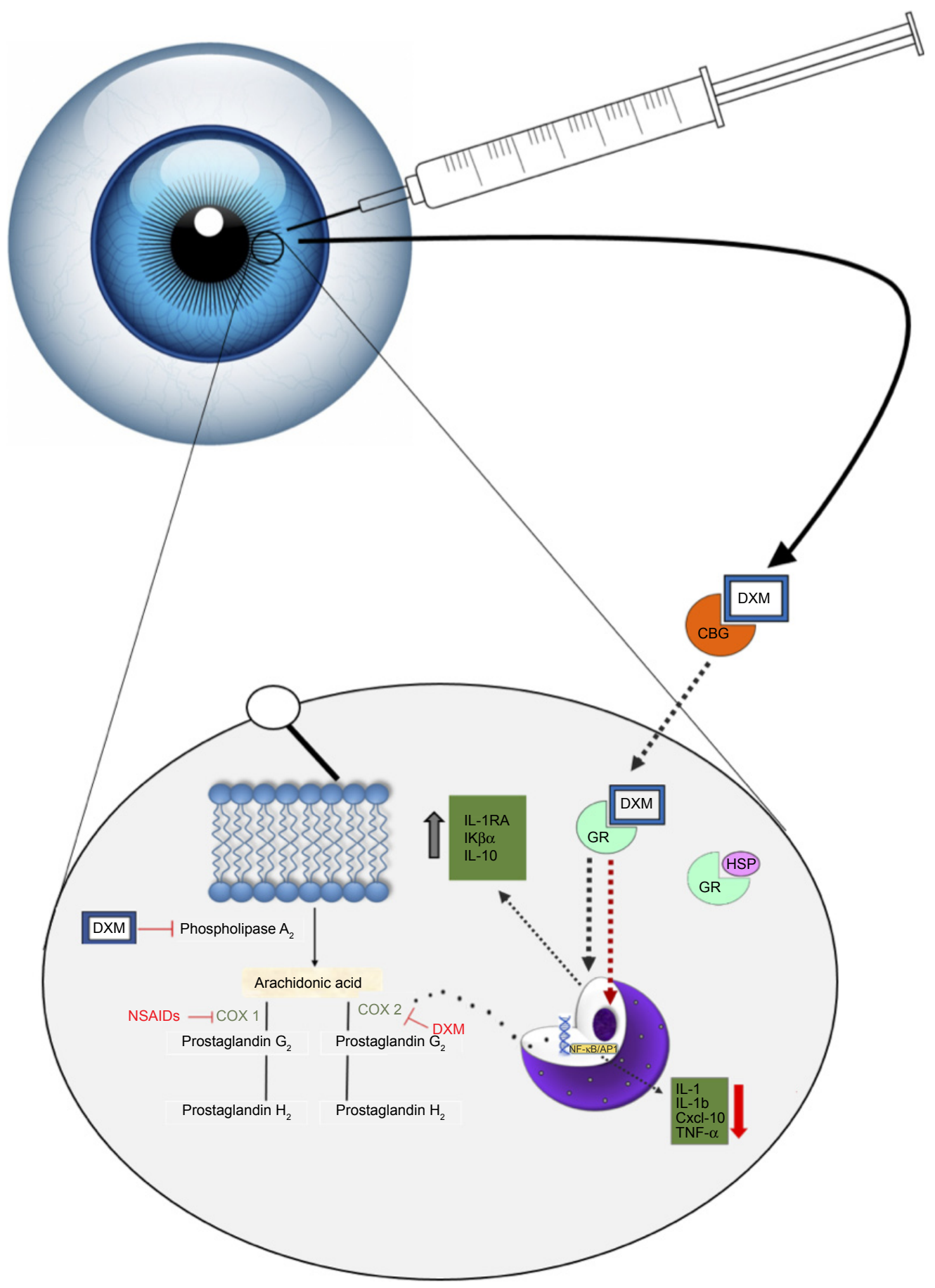

Figure I A model of the mechanism of action upon administration of intraocular DXM.

Notes: The steroid traverses the cellular membrane as a free molecule and interacts with glucocorticoid-receptor. The dimerized complex enters the nucleus where it acts as a transcription factor to upregulate and downregulate certain products to promote its anti-inflammatory effects. Additionally, free DXM inhibits the production of prostaglandins, which are implicated in post-surgical ocular symptoms.

Abbreviations: DXM, dexamethasone; CBG, cortisol-binding globulin; GR, glucocorticoid receptor; HSP, heat-shock protein; IL-IRA, interleukin-I receptor antagonist; IL-I0, interleukin I0; IL-I, interleukin-I; IL-Ib, interleukin-Ib; Cxcl-10, chemokine (C-X-C motif) ligand; TNF- $\alpha$, tumor necrosis factor $\alpha$; COX-I, cyclooxygenase I; COX-2, cycloxygenase 2 . 
eye symptoms that are commonly reported by patients following cataract surgery.

\section{Routes of administration}

An effective DXM treatment regimen needs to maintain a therapeutic concentration at its target site. In aqueous humor, the half-life of DXM is $\sim 3-6$ hours in solution. ${ }^{33}$ The short half-life of DXM is a challenge in dosing, since therapeutic concentrations cannot be maintained for long periods. A discussion of the possible routes of DXM administration after cataract surgery follows, highlighting the advantages and disadvantages of each pharmaceutical preparation (Table 1).

\section{Topical drug delivery}

Topical ophthalmic drug delivery represents the most popular option among cataract surgeons due to its effectiveness and good safety profile in controlling inflammation after cataract surgery. The major advantages of topical drug delivery include noninvasiveness, ease of administration, and there are a variety of new strategies to increase absorption (eg, prodrugs and nanotechnology). Importantly, it is also easier for the surgeon.

When compared to systemic administration, topical delivery confers certain advantages, such as lower systemic absorption and the avoidance of first pass metabolism. ${ }^{34}$ However, upon instillation of eye drops, pre-corneal factors and anatomical barriers negatively influence the bioavailability of topical DXM. Examples of pre-corneal factors include tear lake turnover rate, tear film, blinking, induced lacrimation, and pharmaceutical drainage through the nasolacrimal apparatus. ${ }^{35,36}$ Human tear lake volume is estimated to be seven microliters $(7 \mu \mathrm{L})$ and the tear sac may contain approximately $30 \mu \mathrm{L}$ of an administered eye drop. Given the rapid restoration of tear lake every 2-3 minutes, most of the topical eye drops are washed away within 15-30 seconds after instillation. ${ }^{36,37}$ Additionally, rapid reflex blinking after instillation results in spillage or drainage of a large volume into the nasolacrimal duct and only about $10 \%-20 \%$ of the administered drug is available for corneal absorption, diminishing the total bioavailability in the anterior chamber to $\sim 5 \% .^{34,38}$

Table I A summary of the advantages and disadvantages of various routes of DXM delivery to control post-cataract surgery inflammation

\begin{tabular}{|c|c|c|c|}
\hline \multicolumn{4}{|c|}{ Possible routes of DXM delivery to control inflammation after cataract surgery } \\
\hline Route & Delivery area & Advantages & Disadvantages \\
\hline Topical & $\begin{array}{l}\text { Cornea, sclera, } \\
\text { conjunctiva }\end{array}$ & $\begin{array}{l}\text { - Noninvasive } \\
\text { - Greatest evidence of efficacy and safety } \\
\text { - Easier on surgeon } \\
\text { - Higher patient preference } \\
\text { - Self-administrable } \\
\text { - Many formulations (eg, prodrugs, nanotechnology, } \\
\text { cubosomes, etc.) available to increase bioavailability }\end{array}$ & $\begin{array}{l}\text { - Low patient compliance } \\
\text { - Low bioavailability } \\
\text { - Away from target site } \rightarrow \text { greater amount needed }\end{array}$ \\
\hline Periocular & $\begin{array}{l}\text { Transscleral } \\
\text { (subconjunctival, } \\
\text { sub-tenon, etc.) }\end{array}$ & $\begin{array}{l}\text { - Not as painful as other injections } \\
\text { - Higher therapeutic drug levels } \\
\text { - Closer to target area } \\
\text { - Bypasses corneal barrier }\end{array}$ & $\begin{array}{l}\text { - Greater risk of skin hypopigmentation, subdermal } \\
\text { fat atrophy, extraocular muscle atrophy } \\
\text { - Higher risk for systemic side effects } \\
\text { - Tissue hemorrhage }\end{array}$ \\
\hline Intracameral & $\begin{array}{l}\text { Anterior chamber } \\
\text { or posterior } \\
\text { chamber }\end{array}$ & $\begin{array}{l}\text { - More direct method } \\
\text { - Lesser drug amount needed } \\
\text { - Reduces corneal and systemic side effects seen with } \\
\text { topical steroid application } \\
\text { - Bypasses corneal barrier }\end{array}$ & $\begin{array}{l}\text { - Invasive } \\
\text { - Risk of toxic anterior segment syndrome } \\
\text { - Risk of toxic endothelial cell destruction syndrome } \\
\text { - Tissue hemorrhage }\end{array}$ \\
\hline Intravitreal & Vitreous & $\begin{array}{l}\text { - Bypasses blood-retinal barrier } \\
\text { - Bypasses corneal barrier } \\
\text { - Beneficial in preventing worsening of diabetic } \\
\text { macular edema }\end{array}$ & $\begin{array}{l}\text { - Serious side effects may occur with repeat } \\
\text { injections, such as endophthalmitis and } \\
\text { retinal detachment } \\
\text { - Invasive }\end{array}$ \\
\hline Systemic & $\begin{array}{l}\text { Oral/intramuscular/ } \\
\text { intravitreal }\end{array}$ & $\begin{array}{l}\text { - Higher patient compliance } \\
\text { - Easier on surgeon }\end{array}$ & $\begin{array}{l}\text { - Low bioavailability } \\
\text { - Higher doses required leading to greater likelihood } \\
\text { of toxicity } \\
\text { - Needs to bypass blood-aqueous and blood-retinal } \\
\text { barrier }\end{array}$ \\
\hline
\end{tabular}

Abbreviation: DXM, dexamethasone. 
Anatomical barriers to eye drop administration include the biphasic cornea, conjunctiva, and sclera with the corneal epithelium and stroma representing the most significant barriers to drug absorption. ${ }^{39} \mathrm{DXM}$ is a highly hydrophobic molecule that easily crosses the lipophilic epithelium. However, the drug is prevented from penetrating deeper into ocular tissue due to the presence of a hydrophilic stroma. ${ }^{34}$ Multiple rabbit studies analyzed the corneal surface and found transmembrane efflux pumps (eg, P-glycoprotein, multidrug resistance protein, and breast cancer resistance protein) expressed on the corneal surface restrict drug penetration into the aqueous humor. ${ }^{40-42}$ In contrast, the corneal endothelium contains leaky tight junctions that facilitate passage of DXM between the aqueous humor and stroma, and thus, increases its bioavailability at the target site. ${ }^{24}$ The conjunctiva is another major barrier to drug penetration. This highly vascularized tissue has an abundance of capillaries and the absorption of drug into the conjunctival blood vessels allows significant drug loss into the systemic circulation. In addition, lipophilic absorption of DXM into the conjunctival lymphatics reduces total drug bioavailability. However, given the globular and hydrophobic nature of DXM, it is capable of limited penetration through the sclera and conjunctival epithelial tight junctions; more so than other macromolecules that may be linear and hydrophilic. ${ }^{43}$

\section{Improvements in topical drug delivery method}

A variety of novel strategies, such as prodrugs, nanosuspensions, nanomicelles, and cubosomes, have been developed for topical DXM therapy in order to improve overall bioavailability. A prodrug is a bioreversible derivative of drug molecules and is designed to be therapeutically inactive until enzymatic conversion. ${ }^{34}$ Specifically, these formulations can evade the aforementioned efflux pumps present on the corneal surface. ${ }^{36}$ Civiale et a ${ }^{44}$ investigated a variety of prodrug formulations with DXM and measured the permeability through the corneal surface of rabbit cornea and bovine conjunctival epithelial cells. They reported that permeability of DXM correlated strongly with lipophilicity of the prodrugs. For instance, prodrug formulations, such as acetate, propionate, and butyrate esters, demonstrated higher permeability due to higher lipophilicity with maximum penetration occurring with butyrate esters. Other prodrugs, such as sodium phosphate, have low permeability due to their ionic and hydrophilic structure. Thus, formulations of DXM with butyrate esters or other lipophilic prodrugs may help increase bioavailability of DXM in the anterior chamber. Another strategy to increase bioavailability of topical formulations is via nanoparticle delivery (eg, nanosuspensions, nanomicelles). Nanosuspensions increase saturation solubility of poorly soluble drugs, increase surface area available for dissolution, and allow for greater bioadhesion and corneal penetration. ${ }^{45}$ Kassem et a ${ }^{45}$ demonstrated that DXM nanosuspensions, along with hydrocortisone and prednisolone prepared nanosuspensions, enhanced the rate and extent of drug absorption, with improved drug action when compared to micro-crystalline suspensions and solutions.

Pepić et a ${ }^{46}$ demonstrated increased anterior ocular tissue bioavailability by 2.4 -fold by DXM compounded with nanomicelle formulations using chitosan/pluronic systems relative to unformulated DXM. Nanovehicles of pluronics block copolymers may be used for drug delivery and are combined with chitosan, a cationic polymer. They have proved to be a potent formulation in increasing target area bioavailability. Pluronics significantly improve the solubility and enhance the viscosity of topical drug formulations whereas chitosan improves corneal penetration via the unique ability to open tight junctions. ${ }^{34}$ Similarly, the in vitro permeability coefficient of DXM formulated in cubosomes, the very stable nanoparticles of the biscontinuous cubic lipid crystalline phase, exhibited a 3.5- to 4.5-fold increase compared to DXM sodium phosphate eye drops. Delivery of DXM cubosomes also exhibited a 1.8-fold and 8.0-fold increase in the area under the curve after 240 minutes when measuring DXM in the aqueous humor relative to DXM eye drops and suspensions, respectively. These novel techniques for topical drug delivery represent strategies to bypass significant barriers in drug penetration. Overall, they increase bioavailability, prolong action, and may possibly minimize adverse effects in the anterior chamber. ${ }^{34,45,46}$

\section{Periocular drug delivery}

The periocular routes include subconjunctival, sub-Tenon's, retrobulbar, and peribulbar administration and are all less invasive than the intravitreal route. A subconjunctival injection bypasses the cornea-conjunctiva barrier allowing for greater bioavailability into the anterior chamber than topical delivery affords. However, other studies, ${ }^{47}$ evaluating dynamic barriers, which include conjunctival vessels and lymphatic circulation, document rapid clearance of subconjunctival DXM into the systemic circulation. Hosseini and colleagues ${ }^{47}$ observed the maximum DXM plasma concentration after subconjunctival injection of DXM and 
an intravitreal injection of a similar DXM concentration was $83.3 \mathrm{nM}$ and $9.3 \mathrm{nM}$, respectively. Thus, compared to an intravitreal injection, a subconjunctival injection has greater absorption into the systemic circulation, increasing the risk for possible systemic side effects.

\section{Intravitreal drug delivery}

Patients with pre-existing non proliferative and proliferative diabetic retinopathy are at a great risk of developing postoperative diabetic macular edema (DME) after cataract surgery even if they do not already have it, or worsening of pre-existing DME. ${ }^{48}$ Intravitreal DXM injection given postoperatively or in the infusion fluid (64 mg DXM in $500 \mathrm{cc} /$ balanced salt solution) during surgery offers the advantage of decreasing diabetic macular edema after cataract surgery. ${ }^{49,51}$ Following an intravitreal injection, the drug can be eliminated either via the anterior route from aqueous turnover and uveal outflow or via the posterior route through drug penetration across the blood-retinal barrier. ${ }^{34,36}$ Drugs that are lipophilic with small molecular weight tend to have a decreased half-life. ${ }^{36}$ The halflife of DXM is about 3 hours in the vitreous. ${ }^{50}$ Graham and Peyman demonstrated the safety of administering massive doses of intraocular DXM without producing toxic side effects. ${ }^{15}$ Particularly, it has been demonstrated that up to $4.8 \mathrm{mg}$ of DXM can be injected in normal phakic eyes without producing a toxic reaction. ${ }^{51}$ Although very rare, there is the possibility of significant adverse effects, such as endophthalmitis, retinal detachment, and vitreous hemorrhage from the injection. ${ }^{24}$ Using DXM in the infusion fluid or pre-operative intravitreal DXM for routine and uncomplicated cataract surgery has not been reported in literature, but it is recommended for eyes with diabetic retinopathy (to mitigate exacerbation of DME) and uveitis (to decrease postoperative inflammation and CME). ${ }^{51}$

\section{Intracameral drug delivery}

Although use of intracameral DXM has limited literature regarding its pharmacokinetics, its use intrinsically confers certain advantages. For instance, intracameral DXM is administered at the target site allowing higher drug levels in the anterior chamber. This effectively means less drug is needed to achieve the desired effect and can potentially reduce local side effects, such as increased intraocular pressure. ${ }^{52}$ In addition, it theoretically reduces corneal and systemic side effects that can occur with topical steroid therapy. Studies have shown that when DXM is injected intracamerally, there is a statistically significant increase in efficacy when compared to other routes of administration, such as subconjunctival or sub-Tenon's. ${ }^{21,53}$ In fact, compared to these other modalities of administration, intracameral delivery reduces the risk of skin hypopigmentation, extraocular muscle atrophy, and subdermal fat atrophy. ${ }^{21,52}$ Nonetheless, there are several disadvantages specific to intracameral drug delivery. A possible concern of such drug delivery is toxic anterior segment syndrome (TASS), a sterile postoperative inflammatory reaction caused by a noninfectious substance that enters the anterior segment. ${ }^{54}$ This results in toxic damage to intraocular tissues. Since any medication injected around the eye, and especially, in proximity to the anterior chamber can be implicated with this condition, this adverse effect should certainly be at the forefront of any surgeon's mind. More commonly, this is seen with the use of intracameral anesthetics or antibiotics. To date, there have been no reports of TASS from intracameral injection of DXM (or any other corticosteroid). However, the use of biodegradable sustained-release implants in the anterior chamber (see below) may be a risk factor for TASS. Another adverse effect to consider is the damage to and/or loss of endothelial cells from intracameral injection (discussed in further detail under "Clinical Studies").

\section{Systemic absorption of DXM after intracameral injection}

Aqueous humor outflow ultimately enters the systemic circulation from the episcleral vasculature and is the main source of systemic absorption of drugs injected intracamerally. ${ }^{55}$ Systemic exposure to DXM was evaluated in two studies. ${ }^{56}$ One study reported DXM plasma concentrations at several time intervals within the first 30 days, postoperatively. The intracameral injection of $342 \mathrm{mcg}$ or $517 \mathrm{mcg}$ of DXM at the end of cataract surgery resulted in a plasma concentration on postoperative day 1 that ranged from 0.09 to $0.86 \mathrm{ng} / \mathrm{mL}$ and 0.07 to $1.16 \mathrm{ng} / \mathrm{mL}$, respectively. The second study, reported the day 1 plasma concentration for patients who received $517 \mathrm{mcg}$ of intracameral DXM ranged from 0.349 to $2.79 \mathrm{ng} / \mathrm{mL}$. In both reports, these plasma concentrations were significantly below any known toxic plasma concentration of steroids. ${ }^{57}$ Additionally, very few patients had measurable levels of DXM in plasma at early postoperative intervals, in contrast to periocular and intravitreal injections. ${ }^{47}$ Hence, despite its potency, the use of intracameral DXM is unlikely to cause significant systemic side effects.

\section{Improvements in intracameral drug delivery method}

To control inflammation after cataract surgery, two biodegradable anterior segment drug devices have been developed - one of which has been recently approved by the FDA. These implantable sustained release devices are 
advantageous for anterior segment inflammation because they deliver effective drugs to the target area and reduce the need for frequent intraocular injections. Continuous release is achieved by imbedding a bulk-eroding biodegradable polymer with the DXM. When the polymer is subsequently degraded slowly, the DXM is released. ${ }^{58}$ Since polylactic acid (PLA) takes from 1 to 5 years to degrade, it is combined with polyglycolic acid (PGA) to form poly-lactide-coglycolide (PLGA), which accelerates degradation time. By varying the ratio of PLA to PGA, one can select degradation time. However, since PLGA is a bulk-erosion polymer, it potentially draws significant water into its core, resulting in possible destruction of the medication. Another drawback is auto-catalysis, in which the core polymer is degraded too quickly, resulting in rapid drug release and adverse effects, including a sudden spike in intraocular pressure. ${ }^{58}$

Surodex ${ }^{\circledR}$ (Oculex Pharmaceuticals, Inc., Sunnyvale, CA, USA $)$ is a rod-shaped biodegradable implant $(1.0 \times 0.5 \mathrm{~mm})$ that is placed in either the inferior anterior chamber angle or in the ciliary sulcus of the posterior chamber..$^{59,60}$ The implant is injected using a 25-gauge needle intracamerally and provides a sustained drug release of $60 \mu \mathrm{g}$ of DXM with near zero-order kinetics over 7-10 days. ${ }^{60}$ Surodex significantly reduces the total dose delivered. The total dose in one pellet of Surodex ( $60 \mu \mathrm{g}$ of DXM) is roughly equivalent to that in just one drop of $0.1 \%$ DXM. ${ }^{61}$ The physician can then visually monitor the status and rate of delivery while also tailoring the treatment to the individual patient. Additionally, if there are any significant complications, the implant can be removed if needed. Surodex has completed phase three clinical trials in the US, and although the status of pursuit for FDA approval in the US is currently unknown, Surodex has been popular and approved for use in Singapore, China, and many other countries. ${ }^{62}$

The Dexycu ${ }^{\circledR}$ (Icon Bioscience, Inc. Sunnyvale, CA, USA) treatment is applied as a single intracameral injection at the end of cataract surgery using Icon's Verisome ${ }^{\mathrm{TM}}$ (Icon Bioscience, Inc.) drug delivery technology to dispense a biodegradable extended-release formulation. For up to 21 days, the controlled delivery of DXM is given, although depending on surgeon preference, it can be customized to dispense anywhere from 1 week to over 9 months duration with a single injection. ${ }^{22}$ The procedure involves the surgeon injecting a $5-\mu \mathrm{L}$ droplet of the IBI-10090 suspension of DXM via an intracameral injection into the anterior chamber using the standard 30 -gauge needle. ${ }^{59}$ In early 2018, Dexycu was the first long-acting intracameral product to be approved by the FDA in the US for treating inflammation following cataract surgery. ${ }^{22}$

With the use of these devices, the advantages should be weighed against the disadvantages, which include possible angle or corneal endothelium damage from physical migration of the device, localized damage at the site of implantation, and difficult extraction, if removal is required. ${ }^{16}$ Additionally, if intraocular pressures remain high, the physician may find it more difficult to control and monitor such devices over topical formulations, which may be easily discontinued.

These delivery methods have been implemented for other uses and are very effective. In the treatment of glaucoma, intracameral administration of anti-glaucoma drugs via a sustained-release biodegradable technology has been very efficacious. ${ }^{63}$ In 2015, Navratil et $\mathrm{al}^{64}$ demonstrated sustained intraocular pressure lowering over the course of 6 months using intracameral sustained-release travoprost. Compared to topical administration, a significantly lower aqueous humor concentration of travoprost was needed. ${ }^{63}$ Thus, long-term intracameral drug delivery implants, whether for the use of glaucoma or postoperative cataract inflammation, may be beneficial because they require minimal patient compliance, resulting in increased adherence to therapy.

\section{Clinical studies: intracameral DXM Anterior chamber cells and flare}

In 1999, Tan et al ${ }^{16}$ compared the use of intracameral DXM $(60 \mu \mathrm{g})$ via a Surodex delivery system to $0.1 \%$ DXM eye drops for treatment of postoperative inflammation after cataract surgery using the laser flare photometry instrument as a reproducible assessment of anterior chamber inflammation. ${ }^{65,66}$ Tan's study showed mean postoperative flare values lower in the Surodex eyes at all postoperative visits within 30 days after surgery. During the first 14 days, flare values in eyes receiving DXM eye drops were generally twice those of eyes receiving Surodex. However, by 90 days, there was no significant difference between treatment groups. The slit-lamp inflammation assessment of cell and flare scores was also lower in the Surodex group compared to the DXM eye drop group at all postoperative visits. Despite the fact that there was no statistically significant difference in postoperative inflammation by laser flare between Surodex intracameral DXM and topical steroids, eyes that received Surodex demonstrated less laser flare than those which received topical steroids at all postoperative intervals. ${ }^{18}$ In a later similar study, Tan et al ${ }^{18}$ observed no significant differences in anterior chamber cell and flare assessed by slit lamp between Surodex-treated eyes and topical DXM 0.1\%. In addition, there was no significant difference between laser flare meter readings between the groups throughout each postoperative interval. Gungor et $\mathrm{al}^{20}$ evaluated the difference in postoperative inflammation 
management between intracameral DXM $(0.4 \mathrm{mg} / 0.1 \mathrm{~mL})$ and intracameral triamcinolone acetonide $(2 \mathrm{mg} / 0.05 \mathrm{~mL})$. The two treatment regimens both reduced anterior chamber cells and flare equally and effectively without any statistically significant difference at any postoperative interval. In the recent phase III FDA trial ${ }^{22}$ using the Dexycu delivery system, $63 \%$ and $66 \%$ of patients showed no anterior chamber inflammation at postoperative day 8 when dosed at $343 \mu \mathrm{g}$ or $517 \mu \mathrm{g}$ of DXM, respectively. In contrast, only $25 \%$ of the no-treatment group exhibited anterior chamber clearing at postoperative day 8 . A significant limitation to this study was the lack of comparison to current standard-of-care treatments, such as topical DXM.

Overall, there are a total of six studies that support that injection of intracameral DXM (either with or without the use of a drug delivery system) significantly reduces postoperative anterior chamber cell and flare. ${ }^{17-20,22,67}$

\section{Subjective postoperative inflammatory symptoms}

Studies have shown that generally fewer patients report postoperative inflammatory symptoms when treated with intracameral DXM. For instance, Surodex-treated groups have reported fewer symptoms of discomfort, pain, photophobia, and lacrimation compared to patients on no therapy. ${ }^{17}$ Tan et al ${ }^{18}$ reported a significant decrease in subjective ocular discomfort, photophobia, and lacrimation in eyes treated with Surodex compared to those treated with topical DXM. In contrast, Wadood et $\mathrm{al}^{19}$ observed no difference in inflammatory symptoms of conjunctival hyperemia or ciliary injection in eyes receiving Surodex compared to eyes receiving DXM eye drops. In other studies, decreased subjective inflammatory symptoms are reported in the first week postoperatively in Surodex-treated eyes. Statistical differences are negligible after that first week when compared to eyes receiving DXM eye drops. ${ }^{17,18}$ Another study that used intracameral DXM without a drug delivery system showed no significant difference in postoperative subjective visual symptoms between eyes that received intracameral DXM and those that received topical prednisolone and ketorolac eye drops after cataract surgery. ${ }^{67}$ Since some studies have shown topical NSAIDs are more effective than some potent topical steroids in controlling postoperative inflammation, ${ }^{68-70}$ the use of ketorolac in this study may be a confounding factor resulting in the lack of a significant difference in postoperative inflammatory symptoms. ${ }^{68-70}$

\section{Visual acuity}

Six studies reported a significant improvement in visual acuity in eyes where intracameral DXM was administered. ${ }^{16,18-20,22,67}$
Table 2 A summary of the visual acuity using intracameral DXM and topical steroids at a postoperative interval ( 4-6 weeks). Only studies that quantitatively evaluated visual acuity using the logMAR scale were included

\begin{tabular}{|c|c|c|}
\hline \multicolumn{3}{|c|}{$\begin{array}{l}\text { Postoperative LogMAR after intracameral DXM vs topical } \\
\text { steroid }\end{array}$} \\
\hline Study & LogMAR & Total eyes, $\mathbf{n}$ \\
\hline Gungor et al, $2014^{20}$ (intracameral) & $0.07 \pm N A^{*}$ & 30 \\
\hline Wadood et al, $2004^{19}$ (intracameral) & $0.06 \pm 0.0$ & II \\
\hline Wadood et al, 2004'19 (topical) & $0.15 \pm 0.2$ & 8 \\
\hline Asano et al, $2008^{71}$ (topical) & $-0.066 \pm 0.078$ & 52 \\
\hline Endo et al, $2010^{72}$ (topical) & $-0.04 \pm 0.085$ & 31 \\
\hline Miyanaga et al, $2009^{73}$ (topical) & $0.07 \pm 0.08$ & 22 \\
\hline Wang et al, $2013^{74}$ (topical) & $0.084 \pm 0.1$ & 43 \\
\hline
\end{tabular}

Notes: *Indicates that no standard deviation was reported in this study. Topical steroid use varied between studies. Notably, Gungor 2014 (Intracameral) cohort also received postoperative prednisone acetate drops as part of their standard of care. Wadood 2003 (Intracameral) cohort did not receive any postoperative steroid drops. Abbreviations: DXM, dexamethasone; NA, not available.

Four of the six studies reported qualitative improvement while the other two reported quantitative improvement using logMAR (Table 2). At postoperative days 30 and 60, the mean respective $\log$ MAR was 0.07 and 0.06 for two studies that quantitatively reported the visual acuity of eyes injected with intracameral DXM. ${ }^{19,20}$ In comparison, five studies $^{19,71-74}$ that reported the $\log$ MAR visual acuity after post-operative topical steroid use (the type of steroid varied) ranged from -0.066 to 0.15 after approximately $6-8$ weeks postoperatively (Table 2 ). The postoperative visual acuity did not differ significantly in eyes receiving intracameral DXM compared to those that received topical steroids. Notably, no eye lost best corrected visual acuity with either intracameral or topical DXM use.

\section{Safety and tolerability Intraocular pressure}

One of the problems with administration of intraocular steroids is intraocular pressure (IOP) control. There are several proposed mechanisms of corticosteroid-induced increase in IOP. It is postulated that the glucocorticoid receptor complex causes cross-linking of actin fibers in the trabecular meshwork (TM). There may also be inhibition of proteases and trabecular meshwork endothelial cell phagocytosis that results in impaired drainage from extra material in the TM. ${ }^{75}$ This leads to a steroid-induced increase in intraocular pressure due to decreased outflow and increased outflow resistance. ${ }^{75}$ Since direct administration into the anterior or posterior chamber requires a lower drug concentration, it may be inferred that intracameral drug delivery may not elevate IOP as much as topical delivery. Other studies have demonstrated that the mean IOP elevation is generally greater 
after sub-Tenon's and/or intravitreal steroid administration. Roth et $\mathrm{al}^{76}$ demonstrated that IOP spikes of greater than $20 \mathrm{mmHg}$ occurred more frequently in glaucomatous eyes after intravitreal triamcinolone acetonide.

Similarly, a sub-Tenon's injection of triamcinolone more frequently resulted in ocular hypertension refractory to maximum medical therapy. ${ }^{67,77}$ Topical administration of DXM has also been shown to increase mean IOP. An investigation by Pleyer et $\mathrm{al}^{75}$ demonstrated that $0.1 \%$ of DXM drops administered four-times daily for 6 weeks provoked a mean increase in IOP by $8.6 \mathrm{mmHg}$. The observed increase in IOP with other topical corticosteroids, including newer generation pharmaceuticals (eg, rimexolone, difuprednate, and loteprednol etabonate), had comparable mean changes. ${ }^{75}$ This value is significantly more than the observed IOP increases using intracameral DXM (injection or sustained-released). ${ }^{18,22}$

However, there are an insufficient number of randomizedcontrolled trials evaluating whether there is any difference in postoperative mean IOP between intracameral DXM and topical steroids. The few that have evaluated this outcome show no significant difference (Table 3 ). Other studies using intracameral triamcinolone have reported minimal effect on mean IOP in eyes with no history of glaucoma. ${ }^{78}$ Chang et $\mathrm{al}^{67}$ observed no significant rise in postoperative IOP after intracameral DXM-treated glaucomatous eyes, but compared intracameral triamcinolone to intracameral DXM and observed a smaller increase in intraocular pressure in the initial postoperative period using triamcinolone. ${ }^{20}$ This is presumably secondary to the short half-life of intraocular DXM ( $\sim 3$ hours) and rapid aqueous volume turnover, minimizing the risk of steroid-induced intraocular hypertension. ${ }^{79}$

\section{Corneal endothelial cells}

One of the major complications that stems from an intracameral injection is the loss of corneal endothelial cells as the pharmaceutical contacts these fragile cells. Since this layer may not regenerate, a significant reduction of the endothelial cell count causes impairment of the endothelium pumping, resulting in stromal edema. ${ }^{80} \mathrm{Jamil} \mathrm{et} \mathrm{al}^{21}$ studied the effects of intracameral DXM on corneal endothelial cell loss. They determined there was no difference between endothelial cell numbers after intracameral injection compared to a subconjunctival DXM injection. Three months postoperatively, intracameral DXM-treated eyes demonstrated a mean endothelial cell count of 2,471 whereas subconjunctival DXM had a mean endothelial cell count of 2,496 implying intracameral DXM was not harmful for corneal endothelium. Six other studies ${ }^{17-20,22,67}$ that reported endothelial cell count after intracameral DXM demonstrated no significant cell loss.
In these studies, corneal edema was not significantly higher in eyes that received intracameral DXM compared to those that received placebo. ${ }^{22}$

\section{Adverse events}

When adverse effects occurred in eyes that received intracameral DXM, the complications were generally associated with implantation of the biodegradable device. A few eyes that were implanted with Surodex demonstrated mild localized angle changes in proximity to the pellet remnant. In most cases, there were a few degrees of focal peripheral anterior synechiae, but no pupil distortion was noted. ${ }^{18} \mathrm{~A}$ few patients who were given Surodex treatment had a mild hyphema clot that resolved after day $1 .{ }^{18}$ When Surodex was placed in the ciliary sulcus, migration to the anterior chamber often occurred but this event did not affect visual outcomes. ${ }^{18}$ There was one case that required reposition of iris after traumatic iris prolapse. Eyes that received DXM via the Verisome system had an increased incidence of postoperative dry eyes compared with those without any treatment. However, an adequate analysis could not be made since the patients' preoperative levels of dry eyes were not measured. In eyes that received a single intracameral DXM injection, no significant complications were reported. The frequency of other adverse events such as posterior capsule opacification, cystoid macular edema, vitreous floaters, iritis, and retinal detachment was similar in eyes that received intracameral DXM compared to those that received any other form of postoperative treatment. ${ }^{19,20,22}$

A summary of the visual symptoms, anterior cell and flare scores, intraocular pressure changes, corneal endothelial cell changes, and any adverse effects from the clinical studies using intracameral DXM after cataract surgery is shown in Table 3.

\section{Intracameral DXM: place in therapy}

It has been well documented that intracameral DXM after cataract surgery is a safe and effective option in decreasing postoperative inflammation. Intracameral DXM has a particular advantage over topical steroids in decreasing postoperative visual symptoms and anterior cell and flare scores, although some studies show no difference. Compared to some topical steroids at $0.1 \%$ solution and more, there may be a slightly lower theoretical risk of significant intraocular pressure spikes and systemic absorption. In addition, certain risks that are classically associated with intracameral administration, such as TASS and corneal endothelial cell loss, are much less likely than initially perceived based on current evidence. Nonetheless, there are certain adverse 


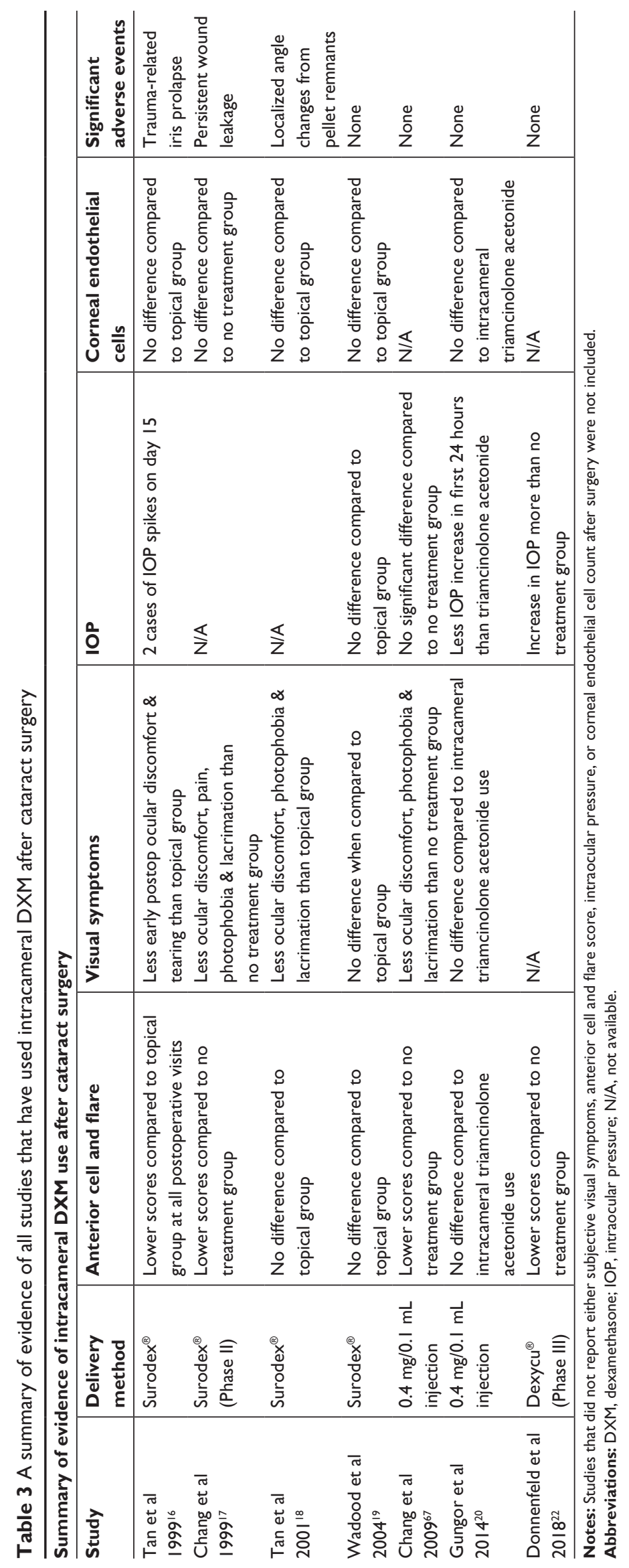


effects associated with intracameral administration. These are seen when placing a biodegradable sustained-release system, and may include the possibility of iris prolapse, surgical hyphema, focal peripheral anterior synechiae, and implant migration. Importantly, these adverse events are easily resolvable and do not cause any measurable vision loss.

The use of intracameral DXM reduces the burden on patients to maintain their postoperative regime with multiple pharmaceutical drops. Most surgeons use a combination of both steroid and NSAID drops and antibiotic drops. Patients have a difficult time tracking these various bottles and remembering the number of corresponding drops. A small study demonstrated that patients preferred a postoperative injection over the self-administration of drops after cataract surgery, presumably due to elimination of the postoperative drop regimen. ${ }^{81}$ There are also significant financial implications with purchasing multiple bottles of topical therapy. We know from prior studies that bottle-tip contamination and the elevated risk of ocular surface trauma is particularly problematic in the early postoperative period in cataract patients. ${ }^{82}$ One study showed that almost $60 \%$ of patients touched their eyes with the bottle tip while instilling the drops, while almost $80 \%$ did not wash their hands before instillation. ${ }^{82}$ In the postoperative setting, this can greatly increase the risk of infection or other adverse events. ${ }^{83}$ Hence, reducing the treatment burden on the patient may help improve patient satisfaction and increase the safety profile. Despite this evidence, topical therapy has been the standard of care for many decades and has an excellent track record of efficacy and safety to support its use. It is noninvasive, compared to the risks associated with intracameral DXM, and there are certain pharmaceuticals that can help improve overall bioavailability at the target site.

In summary, DXM at low doses seldom causes increase in intraocular pressure, when given infrequently, in combination with other anti-inflammatory agents or antibiotics to blunt acute inflammatory processes of the eye. ${ }^{15}$

\section{Conclusion}

The ideal postoperative drug delivery system is one that minimizes systemic side effects, remains confined to a specific target area, minimizes the amount of pharmaceutical needed to reach the therapeutic level, decreases problems of compliance, and maximizes visual recovery. Intracameral DXM provides all these benefits as it controls postsurgical inflammation following cataract surgery. Although it is unlikely that intracameral DXM injections will replace topical medications as the standard of care for post cataract inflammation, the evidence demonstrates that its use offers another safe and effective approach.

\section{Disclosure}

The authors report no conflicts of interest in this work.

\section{References}

1. Resnikoff S, Pascolini D, Etya'ale D, et al. Global data on visual impairment in the year 2002. Bull World Health Organ. 2004;82(11): 844-851.

2. Baltussen R, Sylla M, Mariotti SP. Cost-effectiveness analysis of cataract surgery: a global and regional analysis. Bull World Health Organ. 2004;82(5):338-345.

3. Congdon N, O'Colmain B, Klaver CC, et al. Causes and prevalence of visual impairment among adults in the United States. Arch Ophthalmol. 2004;122(4):477-485.

4. Higashide T, Sugiyama K. Use of viscoelastic substance in ophthalmic surgery - focus on sodium hyaluronate. Clin Ophthalmol. 2008;2(1):21-30.

5. Duan P, Liu Y, Li J. The comparative efficacy and safety of topical non-steroidal anti-inflammatory drugs for the treatment of anterior chamber inflammation after cataract surgery: a systematic review and network meta-analysis. Graefes Arch Clin Exp Ophthalmol. 2017; 255(4):639-649.

6. Dick HB, Schwenn O, Krummenauer F, Krist R, Pfeiffer N. Inflammation after sclerocorneal versus clear corneal tunnel phacoemulsification. Ophthalmology. 2000;107(2):241-247.

7. da Rocha Lima B, Pichi F, Nucci P, Srivastava SK, Lowder CY. Fibrin reaction after uveitic cataract surgery: treatment and prevention. Eur $J$ Ophthalmol. 2014;24(4):626-628.

8. Porela-Tiihonen S, Kaarniranta K, Kokki M, Purhonen S, Kokki H. A prospective study on postoperative pain after cataract surgery. Clin Ophthalmol. 2013;7:1429-1435.

9. Garcia-Gutierrez S, Quintana JM, Aguire U, et al. Impact of clinical and patient-reported outcomes on patient satisfaction with cataract extraction. Health Expect. 2014;17(6):765-775.

10. Feeny D, Spritzer K, Hays RD, et al. Agreement about identifying patients who change over time: cautionary results in cataract and heart failure patients. Med Decis Making. 2012;32(2):273-286.

11. Porela-Tiihonen S, Kokki H, Kaarniranta K, Kokki M. Recovery after cataract surgery. Acta Ophthalmol. 2016;94(Suppl 2):1-34.

12. Greenberg PB, Havnaer A, Oetting TA, Garcia-Ferrer FJ. Cataract surgery practice patterns in the United States Veterans Health Administration. J Cataract Refract Surg. 2012;38(4):705-709.

13. Okeke CO, Quigley HA, Jampel HD, et al. Adherence with topical glaucoma medication monitored electronically the Travatan Dosing Aid study. Ophthalmology. 2009;116(2):191-199.

14. Hermann MM, Ustündag C, Diestelhorst M. Electronic compliance monitoring of topical treatment after ophthalmic surgery. Int Ophthalmol. 2010;30(4):385-390.

15. Graham RO, Peyman GA. Intravitreal injection of dexamethasone. Treatment of experimentally induced endophthalmitis. Arch Ophthalmol. 1974;92(2):149-154.

16. Tan DT, Chee SP, Lim L, Lim AS. Randomized clinical trial of a new dexamethasone delivery system (Surodex) for treatment of post-cataract surgery inflammation. Ophthalmology. 1999;106(2):223-231.

17. Chang DF, Garcia IH, Hunkeler JD, Minas T. Phase II results of an intraocular steroid delivery system for cataract surgery. Ophthalmology. 1999;106(6):1172-1177.

18. Tan DT, Chee SP, Lim L, Theng J, van Ede M. Randomized clinical trial of Surodex steroid drug delivery system for cataract surgery: anterior versus posterior placement of two Surodex in the eye. Ophthalmology. 2001;108(12):2172-2181 
19. Wadood AC, Armbrecht AM, Aspinall PA, Dhillon B. Safety and efficacy of a dexamethasone anterior segment drug delivery system in patients after phacoemulsification. J Cataract Refract Surg. 2004;30(4): 761-768.

20. Gungor SG, Bulam B, Akman A, Colak M. Comparison of intracameral dexamethasone and intracameral triamcinolone acetonide injection at the end of phacoemulsification surgery. Indian J Ophthalmol. 2014;62(8):861.

21. Jamil AZ, Ahmed A, Mirza KA. Effect of intracameral use of dexamethasone on corneal endothelial cells. J Coll Physicians Surg Pak. 2014;24(4):245-248.

22. Donnenfeld E, Holland E. Dexamethasone intracameral drug-delivery suspension for inflammation associated with cataract surgery: a randomized, placebo-controlled, Phase III trial. Ophthalmology. 2018; 125(6):799-806.

23. Coursey TG, Henriksson JT, Marcano DC, et al. Dexamethasone nanowafer as an effective therapy for dry eye disease. $J$ Control Release. 2015;213:168-174.

24. Rodríguez Villanueva J, Rodríguez Villanueva L, Guzmán Navarro M. Pharmaceutical technology can turn a traditional drug, dexamethasone into a first-line ocular medicine. A global perspective and future trends. Int J Pharm. 2017;516(1-2):342-351.

25. Mogensen TH, Berg RS, Paludan SR, Østergaard L. Mechanisms of dexamethasone-mediated inhibition of Toll-like receptor signaling induced by Neisseria meningitidis and Streptococcus pneumoniae. Infect Immun. 2008;76(1):189-197.

26. Prabhu P, Dubey A, Parth V, Ghate V. Investigation of hydrogel membranes containing combination of gentamicin and dexamethasone for ocular delivery. Int J Pharm Investig. 2015;5(4):214.

27. Kulkarni PS, Mancino M. Studies on intraocular inflammation produced by intravitreal human interleukins in rabbits. Exp Eye Res. 1993; 56(3):275-279.

28. Kulkarni PS, Srinivasan BD. Cyclooxygenase and lipoxygenase pathways in anterior uvea and conjunctiva. Prog Clin Biol Res. 1989;312:39-52.

29. McGhee CN, Dean S, Danesh-Meyer H. Locally administered ocular corticosteroids: benefits and risks. Drug Saf. 2002;25(1):33-55.

30. Abadia B, Calvo P, Ferreras A, Bartol F, Verdes G, Pablo L. Clinical applications of dexamethasone for aged eyes. Drugs Aging. 2016;33(9): 639-646.

31. Masferrer JL, Kulkarni PS. Cyclooxygenase-2 inhibitors: a new approach to the therapy of ocular inflammation. Surv Ophthalmol. 1997;41(Suppl2): S35-S40.

32. Raz A, Wyche A, Needleman P. Temporal and pharmacological division of fibroblast cyclooxygenase expression into transcriptional and translational phases. Proc Natl Acad Sci U S A. 1989;86(5):1657-1661.

33. Bhagat R, Zhang J, Farooq S, Li XY. Comparison of the release profile and pharmacokinetics of intact and fragmented dexamethasone intravitreal implants in rabbit eyes. J Ocul Pharmacol Ther. 2014;30(10):854-858.

34. Cholkar K, Patel SP, Vadlapudi AD, Mitra AK. Novel strategies for anterior segment ocular drug delivery. J Ocul Pharmacol Ther. 2013;29(2): $106-123$.

35. Tasman W, Jaeger EA, editors. Duane's Ophthalmology. Philadelphia, PA: Lippincott Williams \& Wilkins; 2009.

36. Gaudana R, Ananthula HK, Parenky A, Mitra AK. Ocular drug delivery. AAPS J. 2010;12(3):348-360.

37. Ahmed I, Patton TF. Importance of the noncorneal absorption route in topical ophthalmic drug delivery. Invest Ophthalmol Vis Sci. 1985;26(4): 584-587.

38. Urtti A, Pipkin J, Rork G, Sendo T, Finne U, Repta A. Controlled drug delivery devices for experimental ocular studies with timolol 2. Ocular and systemic absorption in rabbits. Int J Pharm. 1990;61(3): 241-249.

39. Mannermaa E, Vellonen KS, Urtti A. Drug transport in corneal epithelium and blood-retina barrier: emerging role of transporters in ocular pharmacokinetics. Adv Drug Deliv Rev. 2006;58(11): $1136-1163$.
40. Karla PK, Earla R, Boddu SH, Johnston TP, Pal D, Mitra A. Molecular expression and functional evidence of a drug efflux pump (BCRP) in human corneal epithelial cells. Curr Eye Res. 2009;34(1):1-9.

41. Karla PK, Pal D, Mitra AK. Molecular evidence and functional expression of multidrug resistance associated protein (MRP) in rabbit corneal epithelial cells. Exp Eye Res. 2007;84(1):53-60.

42. Dey S, Patel J, Anand BS, et al. Molecular evidence and functional expression of P-glycoprotein (MDR1) in human and rabbit cornea and corneal epithelial cell lines. Invest Ophthalmol Vis Sci. 2003; 44(7):2909-2918.

43. Kim SH, Lutz RJ, Wang NS, Robinson MR. Transport barriers in transscleral drug delivery for retinal diseases. Ophthalmic Res. 2007; 39(5):244-254.

44. Civiale C, Bucaria F, Piazza S, Peri O, Miano F, Enea V. Ocular permeability screening of dexamethasone esters through combined cellular and tissue systems. J Ocul Pharmacol Ther. 2004;20(1):75-84.

45. Kassem MA, Abdel Rahman AA, Ghorab MM, Ahmed MB, Khalil RM. Nanosuspension as an ophthalmic delivery system for certain glucocorticoid drugs. Int J Pharm. 2007;340(1-2):126-133.

46. Pepić I, Hafner A, Lovrić J, Pirkić B, Filipović-Grcić J. A nonionic surfactant/chitosan micelle system in an innovative eye drop formulation. J Pharm Sci. 2010;99(10):4317-4325.

47. Hosseini K, Matsushima D, Johnson J, et al. Pharmacokinetic study of dexamethasone disodium phosphate using intravitreal, subconjunctival, and intravenous delivery routes in rabbits. $J$ Ocul Pharmacol Ther. 2008;24(3):301-308.

48. Kim SJ, Equi R, Bressler NM. Analysis of macular edema after cataract surgery in patients with diabetes using optical coherence tomography. Ophthalmology. 2007;114(5):881-889.

49. Calvo P, Ferreras A, Al Adel F, Dangboon W, Brent MH. Effect of an intravitreal dexamethasone implant on diabetic macular edema after cataract surgery. Retina. 2018;(38)3:490-496.

50. Paris CL, Peyman GA, Gremillion CM, Blinder KJ. Intravitreal dexamethasone following vitreous surgery. Int Ophthalmol. 1991;15(3): 173-174.

51. Nabih M, Peyman GA, Tawakol ME, Naguib K. Toxicity of high-dose intravitreal dexamethasone. Int Ophthalmol. 1991;15(4):233-235.

52. Kanski JJ. Clinical ophthalmology. A Systematic Approach; 2nd ed. Burlington, MA: Butterworth-Heinemann; 2007:629.

53. Vengatesan MR, Mittal V. Nanoparticle-and Nanofiber-Based Polymer Nanocomposites: An Overview. In: Wiley Spherical and Fibrous Filler Composites. Weinheim, Germany: Wiley-VCH; 2016;1:1-38.

54. Mamalis N, Edelhauser HF, Dawson DG, Chew J, Leboyer RM, Werner L. Toxic anterior segment syndrome. J Cataract Refract Surg. 2006;32(2):324-333.

55. Goel M, Picciani RG, Lee RK, Bhattacharya SK. Aqueous humor dynamics: a review. Open Ophthalmol J. 2010;4:52-59.

56. United States Food and Drug Administration. Dexycu. Available from: https://www.accessdata.fda.gov/drugsatfda_docs/ label/2018/208912s000lbl.pdf. Accessed June 3, 2018.

57. Shaikh S, Verma H, Yadav N, Jauhari M, Bullangowda J. Applications of steroid in clinical practice: a review. ISRN Anesthesiol. 2012; 2012(7):1-11.

58. Lee DJ. Intraocular implants for the treatment of autoimmune uveitis. J Funct Biomater. 2015;6(3):650-666.

59. Haghjou N, Soheilian M, Abdekhodaie MJ. Sustained release intraocular drug delivery devices for treatment of uveitis. J Ophthalmic Vis Res. 2011;6(4):317-319.

60. Lee SS, Hughes P, Ross AD, Robinson MR. Biodegradable implants for sustained drug release in the eye. Pharm Res. 2010;27(10): 2043-2053.

61. Lee SY, Chee SP, Balakrishnan V, Farzavandi S, Tan DT. Surodex in paediatric cataract surgery. Br J Ophthalmol. 2003;87(11): 1424-1426.

62. Wang J, Jiang A, Joshi M, Christoforidis J. Drug delivery implants in the treatment of vitreous inflammation. Mediators Inflamm. 2013;2013: $1-8$. 
63. Durairaj C. Ocular pharmacokinetics. Handb Exp Pharmacol. 2017;242: $31-55$.

64. Navratil T, Garcia A, Tully J, et al. Preclinical Evaluation of ENV515 (travoprost) Intracameral Implant-Clinical Candidate for Treatment of Glaucoma Targeting Six-Month Duration of Action. Investigative Ophthalmology \& Visual Science. 2014:55(13):3548-3548.

65. El-Maghraby A, Marzouki A, Matheen TM, Souchek J, van der Karr M. Reproducibility and validity of laser flare/cell meter measurements of intraocular inflammation. J Cataract Refract Surg. 1993;19(1): $52-55$.

66. Sawa M, Tsurimaki Y, Tsuru T, Shimizu H. New quantitative method to determine protein concentration and cell number in aqueous in vivo. Jpn J Ophthalmol. 1988;32(2):132-142.

67. Chang DT, Herceg MC, Bilonick RA, Camejo L, Schuman JS, Noecker RJ. Intracameral dexamethasone reduces inflammation on the first postoperative day after cataract surgery in eyes with and without glaucoma. Clin Ophthalmol. 2009;3(1):345-355.

68. Kessel L, Tendal B, Jørgensen KJ, et al. Post-cataract prevention of inflammation and macular edema by steroid and nonsteroidal antiinflammatory eye drops: a systematic review. Ophthalmology. 2014; 121(10):1915-1924.

69. Hirneiß C, Neubauer AS, Kampik A, Schönfeld CL. Comparison of prednisolone $1 \%$, rimexolone $1 \%$ and ketorolac tromethamine $0.5 \%$ after cataract extraction. A prospective, randomized, doublemasked study. Graefe's Arch Clin Exp Ophthalmol. 2005;243(8) 768-773.

70. El-Harazi SM, Ruiz RS, Feldman RM, Villanueva G, Chuang AZ. A randomized double-masked trial comparing ketorolac tromethamine $0.5 \%$, diclofenac sodium $0.1 \%$, and prednisolone acetate $1 \%$ in reducing post-phacoemulsification flare and cells. Ophthalmic Surg Lasers. 1998;29(7):539-544.

71. Asano S, Miyake K, Ota I, et al. Reducing angiographic cystoid macular edema and blood-aqueous barrier disruption after smallincision phacoemulsification and foldable intraocular lens implantation: multicenter prospective randomized comparison of topical diclofenac $0.1 \%$ and betamethasone 0.1\%. J Cataract Refract Surg. 2008;34(1): $57-63$.
72. Endo N, Kato S, Haruyama K, Shoji M, Kitano S. Efficacy of bromfenac sodium ophthalmic solution in preventing cystoid macular oedema after cataract surgery in patients with diabetes. Acta Ophthalmol. 2010; 88(8):896-900.

73. Miyanaga M, Miyai T, Nejima R, Maruyama Y, Miyata K, Kato S. Effect of bromfenac ophthalmic solution on ocular inflammation following cataract surgery. Acta Ophthalmol. 2009;87(3):300-305.

74. Wang QW, Yao $\mathrm{K}, \mathrm{Xu} \mathrm{W}$, et al. Bromfenac sodium $0.1 \%$, fluorometholone $0.1 \%$ and dexamethasone $0.1 \%$ for control of ocular inflammation and prevention of cystoid macular edema after phacoemulsification. Ophthalmologica. 2013;229(4):187-194.

75. Pleyer U, Ursell PG, Rama P. Intraocular pressure effects of common topical steroids for post-cataract inflammation: are they all the same? Ophthalmol Ther. 2013;2(2):55-72.

76. Roth DB, Realini T, Feuer WJ, et al. Short-term complications of intravitreal injection of triamcinolone acetonide. Retina. 2008;28(1):66-70.

77. Inatani M, Iwao K, Kawaji $\mathrm{T}$, et al. Intraocular pressure elevation after injection of triamcinolone acetonide: a multicenter retrospective casecontrol study. Am J Ophthalmol. 2008;145(4):676-681.

78. Karalezli A, Borazan M, Akova YA. Intracameral triamcinolone acetonide to control postoperative inflammation following cataract surgery with phacoemulsification. Acta Ophthalmol. 2008;86(2):183-187.

79. Kwak HW, D'Amico DJ. Evaluation of the retinal toxicity and pharmacokinetics of dexamethasone after intravitreal injection. Arch Ophthalmol. 1992;110(2):259-266.

80. Dineen B, Bourne RR, Jadoon Z, et al. Causes of blindness and visual impairment in Pakistan. The Pakistan national blindness and visual impairment survey. Br J Ophthalmol. 2007;91(8):1005-1010.

81. Fisher BL, Potvin R. Transzonular vitreous injection vs a single drop compounded topical pharmaceutical regimen after cataract surgery. Clin Ophthalmol. 2016;10:1297-1303.

82. An JA, Kasner O, Samek DA, Lévesque V. Evaluation of eyedrop administration by inexperienced patients after cataract surgery. $J$ Cataract Refract Surg. 2014;40(11):1857-1861.

83. Brown MM, Brown GC, Spaeth GL. Improper topical self-administration of ocular medication among patients with glaucoma. Can J Ophthalmol. 1984;19(1):2-5.
Clinical Ophthalmology

\section{Publish your work in this journal}

Clinical Ophthalmology is an international, peer-reviewed journal covering all subspecialties within ophthalmology. Key topics include: Optometry; Visual science; Pharmacology and drug therapy in eye diseases; Basic Sciences; Primary and Secondary eye care; Patient Safety and Quality of Care Improvements. This journal is indexed on

\section{Dovepress}

PubMed Central and CAS, and is the official journal of The Society of Clinical Ophthalmology (SCO). The manuscript management system is completely online and includes a very quick and fair peer-review system, which is all easy to use. Visit http://www.dovepress.com/ testimonials.php to read real quotes from published authors. 